Research Paper

\title{
The Optimal Application of Transrectal Ultrasound in Staging of Rectal Cancer Following Neoadjuvant Therapy: A Pragmatic Study for Accuracy Investigation
}

\author{
Yufeng Ren"1, Jinning Ye2\#, Yan Wang33, Weixin Xiong2, Jianbo Xu'2,4, Yulong He²,4, Shirong Cai²,4, Min \\ $\operatorname{Tan}^{2,4}$, Yujie Yuan ${ }^{2,4}$ \\ 1. Department of Radiation Oncology, The First Affiliated Hospital, Sun Yat-Sen University, Guangzhou, P.R. China \\ 2. Center of Gastrointestinal Surgery, The First Affiliated Hospital, Sun Yat-Sen University, Guangzhou, P.R. China \\ 3. Department of Medical Ultrasonics, Institute of Diagnostic and Interventional Ultrasound, The First Affiliated Hospital, Sun Yat-Sen University, \\ Guangzhou, P.R. China \\ 4. Center of Gastric cancer, Sun Yat-Sen University, Guangzhou, P.R. China \\ \#These authors contributed equally to this study \\ $\square$ Corresponding author: Yujie Yuan, MD, PhD, 58, 2nd Zhongshan Road, Guangzhou, 510080, P.R. China. Email: yuanyj5@mail.sysu.edu.cn; Phone: \\ +8615018492852; Fax: +862087331059.
}

(c) Ivyspring International Publisher. This is an open access article distributed under the terms of the Creative Commons Attribution (CC BY-NC) license (https://creativecommons.org/licenses/by-nc/4.0/). See http://ivyspring.com/terms for full terms and conditions.

Received: 2017.09.03; Accepted: 2017.12.29; Published: 2018.02.11

\begin{abstract}
Background: Transrectal ultrasound (TRUS) is a cost-effective test for preoperative assessment of rectal cancer. However, whether the accuracy of TRUS staging is correlated with tumor location remains obscured. This study is designed to explore their relationship and confirm an optimal application of TRUS in rectal cancer restaging.

Methods: From 2005 to 2011, rectal cancer patients with TRUS data were retrospectively reviewed. Patients were divided into five groups according to tumor-involved rectal segment (SEG) above the anal verge: SEG I 1-3cm, II 3-6cm, III 6-9cm, IV 9-12cm, and V 12-16 cm. The accuracy and long-term outcomes of tumor staging were compared between ultrasonographic and pathological stages.

Results: 219 patients were included, with 55 (25.1\%) in SEG I, 123 (56.2\%) in SEG II, 32 (14.6\%) in SEG III, $4(1.8 \%)$ in SEG IV and $5(2.3 \%)$ in SEG V. The overall accuracy of TRUS staging was remarkably superior to clinical staging by CT $(64.8 \%$ vs. $34.7 \%, P<0.001)$, with $70.3 \%$ and $82.2 \%$ for ultrasonographic $\mathrm{T}$ and $\mathrm{N}$ stages respectively. The accuracy of TRUS reached its peak value when tumors were located in SEG II. The 5-year overall survival had no significant difference between TRUS and pathology staging for all stages. A cox regression analysis indicated that high levels of CEA and tumor location were risk factors of inaccurate staging.

Conclusions: TRUS is still a valuable examination for restaging of rectal cancer after neoadjuvant therapy. The application of TRUS would be optimal for rectal cancer located $3-6 \mathrm{~cm}$ above the anal verge.
\end{abstract}

Key words: transrectal ultrasonography; tumor staging; rectal cancer; accuracy; outcomes.

\section{Introduction}

Colorectal cancer is the third most common malignant neoplasm, being responsible for approximately $8-9 \%$ of deaths, as shown by official statistics in the USA for 2016 [1]. Preoperative evaluation is essential in decision making of management of colorectal cancer, especially for surgical treatment. As compared with colon cancer, rectal cancer could be managed with various interventions due to the complexity of rectal anatomy and tumor involving structures. For the last two 
decades, the development of multidisciplinary team (MDT) discussion has promoted a systemic treatment of rectal cancer. To date, all surgical procedures, such as extended resection and minimally regional excision, should be tailored based on accurate preoperative assessments using all sorts of staging tools [2-4].

Those staging modalities for rectal cancer include digital rectal exam, transrectal ultrasound (TRUS), computed tomography (CT), positron emission tomography (PET) and magnetic resonance imaging (MRI) with or without endorectal coil $[5,6]$. TRUS can identify the circumferential resection margin of low rectal tumors confined to the anterior wall, with comparable results to MRI findings (overall accuracy $87.5 \%$, negative predictive value $95.6 \%$ ) [7]. Current evidence shows that TRUS is the most cost-effective and preferred method for loco-regional staging of rectal cancer [8]. A recent meta-analysis designed to explore the accuracy of ultrasonographic $\mathrm{T}$ staging in rectal cancer indicates that TRUS has a sensitivity of $81-96 \%$ and a specificity of $91-98 \%$ [9]. Moreover, TRUS has also demonstrated its efficacy in detecting metastatic lymph nodes (LNs) and local recurrence $[10,11]$.

To date, TRUS has become an optional examination for preoperative staging of rectal cancer; however, studies designed to explore the relationship between its accuracy and tumor location are seldom available. Whether the accuracy of TRUS is correlated with tumor location remains obscured, especially following neoadjuvant therapy (NAT). The current study is designed to investigate their potential relationship and detect an optimal application of TRUS in restaging rectal cancer after NAT.

\section{Patients and Methods}

\section{Patients}

This study was a single-center retrospective analysis of a prospectively collected database of rectal cancer patients. Those subjects treated with induction therapy and radical tumor resection from January 2005 to September 2011 were reviewed. All perioperative data and long-term follow up outcomes were extracted from our dataset and hospital records. The study protocol was approved by the Institutional Review Board of our hospital. All included subjects were provided written informed consent prior to any treatment.

The study selection criteria, primarily as previously described [7, 12], included as follows: 1) confirmed histological diagnosis of rectal adenocarcinoma; 2) no distant metastasis such as non-regional LN, liver, adrenal glands, bone, lungs, brain or peritoneum; 3) tumor-involved segment could be completely passed with colonoscopy to allow TRUS assessment after NAT. Exclusion criteria included an emergency operation due to bowel obstruction or uncontrolled rectal bleeding, a history of previous cancer treatment or infection within the previous one month, any record of immuneassociated disease, or less than three months of survival after radical surgery.

\section{Treatment schemes}

Consecutive patients admitting to our center first underwent a standard protocol of investigation, including endoscopy, multi-sliced spiral CT (MSCT), TRUS and additional PET if indicated. After that, they were discussed in a specialist MDT meeting to determine tumor stage and treatment plan. The perioperative staging of rectal cancer was based on the American Joint Committee TNM staging (the $7^{\text {th }}$ edition), adding the coefficient of error resulting from the specificity of TRUS. Due to this feature, the term ultrasonographic TNM (uTNM) was used in the preoperative evaluation as previously described (Table 1) [13]. However, MRI was not employed as a main staging tool during that period.

Table 1. The preoperative TNM staging standards in current study

\begin{tabular}{|c|c|c|}
\hline $\begin{array}{l}\text { TNM } \\
\text { staging }\end{array}$ & MSCT (cTNM) & TRUS (uTNM) \\
\hline \multicolumn{3}{|l|}{ T stage } \\
\hline 0 & $\begin{array}{l}\text { No detectable enhanced lesion } \\
\text { in pelvis }\end{array}$ & No invasive-lesion detected \\
\hline $\mathrm{T} 1$ & $\begin{array}{l}\text { Intraluminal polypoid } \\
\text { neoplasm, without } \\
\text { enhancement of bowel wall }\end{array}$ & $\begin{array}{l}\text { Invasive lesion with mucosal } \\
\text { and submucosal confinement }\end{array}$ \\
\hline $\mathrm{T} 2$ & $\begin{array}{l}\text { Partial enhancement of bowel } \\
\text { wall near the detectable mass }\end{array}$ & $\begin{array}{l}\text { Lesion confined to the } \\
\text { muscularis propria } \\
\text { Invasion of the second } \\
\text { hypoechogenic layer }\end{array}$ \\
\hline $\mathrm{T} 3$ & $\begin{array}{l}\text { Thickening of bowel wall (more } \\
\text { than } 0.5 \mathrm{~cm} \text { ), without invasion of } \\
\text { surrounding structures }\end{array}$ & $\begin{array}{l}\text { Lesion penetrating all rectal } \\
\text { layers } \\
\text { Invasion of the perirectal fat, } \\
\text { without pelvic organ invasion }\end{array}$ \\
\hline $\mathrm{T} 4$ & $\begin{array}{l}\text { Invasion of surrounding tissue } \\
\text { (prostate, vagina, uterus, cervix, } \\
\text { bladder, etc.) }\end{array}$ & $\begin{array}{l}\text { Invasion of pelvic organ } \\
\text { (prostate, vagina, uterus, } \\
\text { cervix, bladder, etc.) }\end{array}$ \\
\hline \multicolumn{3}{|l|}{$\mathrm{N}$ stage } \\
\hline N0 & No visible lymph node & Undetectable adenopathy \\
\hline N1 & $\begin{array}{l}\text { Up to three lymph nodes } \\
\text { (diameter } \geq 8 \mathrm{~mm} \text { ) with } \\
\text { distributed enhancement }\end{array}$ & $\begin{array}{l}\text { Up to three detectable tumor } \\
\text { lymph nodes with circular } \\
\text { hypoechoic structures } \\
\text { (diameter } \geq 3 \mathrm{~mm} \text { ) }\end{array}$ \\
\hline N2 & $\begin{array}{l}\text { More than three detectable } \\
\text { lymph nodes (diameter } \geq 8 \mathrm{~mm} \text { ), } \\
\text { with distributed enhancement }\end{array}$ & $\begin{array}{l}\text { More than three detectable } \\
\text { tumor lymph nodes with } \\
\text { circular hypoechoic structures } \\
\text { (diameter } \geq 3 \mathrm{~mm} \text { ) }\end{array}$ \\
\hline \multicolumn{3}{|l|}{ M stage } \\
\hline M0 & No distant metastases & Not available \\
\hline M1 & $\begin{array}{l}\text { Distant metastases (omentum, } \\
\text { peritoneum, liver, bone, etc.) }\end{array}$ & Not available \\
\hline
\end{tabular}


In this study, each patient would be allocated a clinical stage, known as cTNM by MSCT. Additional TRUS staging (uTNM) for local assessment was supplied to decide whether induction therapy required or not. Of note, NAT, including chemoradiotherapy, radiotherapy and chemotherapy alone, was performed for all included patients. Specifically, TRUS was performed using a two-dimensional ultrasound scanner (SSA 790A, Toshiba ${ }^{\odot}$, Japan), with rigid rectal probe $(5-10 \mathrm{MHz}, 3 \mathrm{~cm}$ in width) measured maximal $16 \mathrm{~cm}$ in length from the anal verge. Specialized ultrasonologists with at least 5-year experience of pelvic US performed the examination and evaluated uTNM stage meanwhile, with patient information blinded during the examination.

Patients who received neoadjuvant radiotherapy would be reassessed by using MSCT (thorax, abdomen and pelvis) and TRUS routinely. Of note, the newly ultrasonographic or clinical stage, rather than the initial one, was employed for comparison of the pathological stage. In nearly all cases, surgery was suggested within six weeks after NAT. Thereafter, a radical resection by open or laparoscopic surgery was scheduled, with a pathological TNM stage (ypTNM) confirmed by tumor histology. Downstaging was defined as a reduction in $\mathrm{T}$ or $\mathrm{N}$ stage of ypTNM compared with cTNM or uTNM.

After surgery, an adjuvant chemotherapy alone was suggested for patients with pathological stage IIB and above, which was routinely initiated 3-4 weeks later. No additional radiotherapy was performed unless a regional recurrence occurred. Follow-up was typically every three months for the first year after the surgery, every six months for the second year and twice a year thereafter [14]. Similar follow-up procedures took place with a medical oncologist and radiation oncologist. There was no protocol on obtaining imaging, but CT-scan with enhanced contrast, TRUS or PET-CT scan was selected for recurrence surveillance within the follow-up period.

To identify the accuracy of TRUS for rectal cancer staging, the rectum was intentionally divided into five segments from $1 \mathrm{~cm}$ proximal to the anal verge until the maximal detectable length $(16 \mathrm{~cm})$ of ultrasonic probe. In brief, segment (SEG) I ranged from $1-3 \mathrm{~cm}$ (including $3 \mathrm{~cm}$ ), as SEG II $3-6 \mathrm{~cm}$, SEG III $6-9 \mathrm{~cm}$, SEG IV 9-12cm and SEG V 12-16cm, respectively. This separation method was modified from previous researches in which the rectum was divided into four parts (1. Anorectal transition, $0-4 \mathrm{~cm}$; 2. Distal rectum, $4-8 \mathrm{~cm} ; 3$. Middle rectum, $8-12 \mathrm{~cm} ; 4$. Proximal rectum, $>12 \mathrm{~cm}$ ) $[15,16]$. During the TRUS examination, the distance from distal tumor (lower margin) to anal verge was recorded to identify involved rectal segment, with tumor thickness recorded meanwhile. Patients with the same involved segment were grouped together for further analysis.

The primary outcomes of this study were the accuracy of preoperative uTNM stage in each rectal segment as the reference to pathological TNM stage. The secondary outcomes included long-term survival and some risk factors correlated with the inaccuracy of ultrasonographic staging.

\section{Statistical analysis}

Descriptive statistics were used to present demographics and oncologic outcomes, with expressed as means $\pm S D$ unless otherwise specified. Medians with range values were displayed for non-normally distributed data. Categorical data were expressed as counts and proportion. Continuous variables and percentages were compared between groups by using the Kruskal-wallis test or Chi-square test, respectively. Univariate survival analysis was performed with Cox regression for continuous variables and Kaplan-Meier method for binary variables. The diagnostic accuracy of each tumor staging was evaluated with receptor observing curve (ROC) analysis. All data analyses were completed using IBM SPSS (Ver. 23.0; Chicago, IL, USA). A P value $<0.05$ (two-sided) was considered statistically significant.

\section{Results}

From January 2005 to September 2011, 331 patients who had rectal cancer and underwent TRUS examination for preoperative evaluation were initially enrolled. Among those, 34 patients who had synchronous liver metastasis, 48 patients who had severe rectal obstruction, and 30 patients who had other exclusion conditions were filtered out from this study. The flow chart was shown in Figure 1. In all, the remaining 219 subjects were included for final analysis, with the baseline demographics summarized in Table 2. Of note, patients were intentionally divided into five groups according to tumor location, with 55 (25.1\%) in SEG I, 123 (56.2\%) in SEG II, 32 $(14.6 \%)$ in SEG III, four $(1.8 \%)$ in SEG IV and five $(2.3 \%)$ in SEG V. The median age was 56 (range, 18-80) years, with $71.2 \%$ of male subjects included. The median tumor location prior to any treatment was 5.0 (range, 1.0-16.0) $\mathrm{cm}$ distant to the anal verge, with the same median distance detected after NAT (median, $5.0 \mathrm{~cm}$; range, $1.0-11.0 \mathrm{~cm})$. Of note, nine $(4.1 \%)$ patients in SEG IV and $\mathrm{V}$ received systemic chemotherapy alone before surgery. 


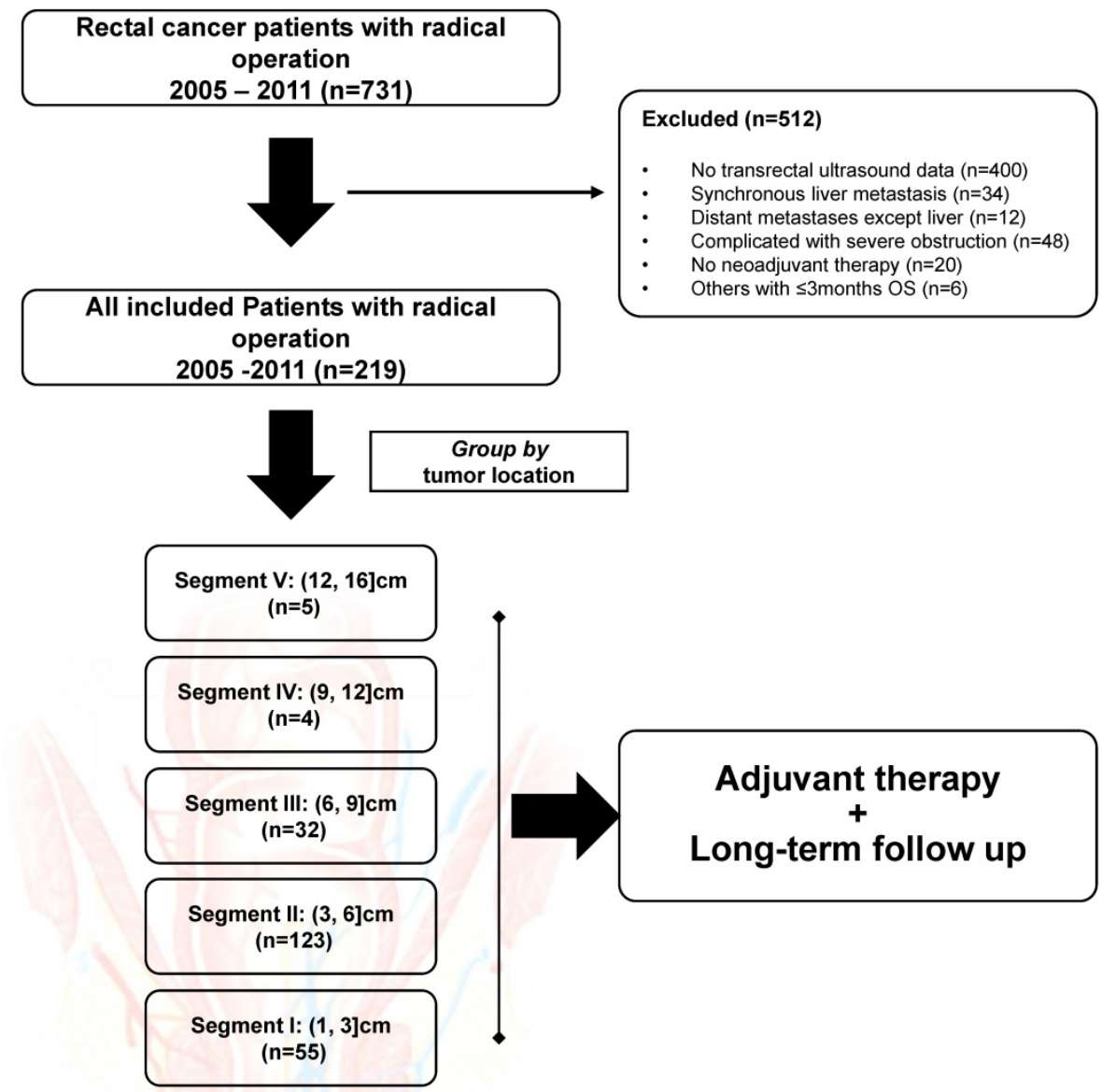

Figure 1. The flow chart of this retrospective study. In all, 512 patients were excluded from final analysis. All included patients were grouped by tumor location, with five rectal segments used for comparison.

Table 2. Demographics and clinical characteristics of included patients

\begin{tabular}{|c|c|c|c|c|c|c|}
\hline Characteristic & $\begin{array}{l}\text { The Pooled } \\
(n=219)\end{array}$ & $\begin{array}{l}\text { SEG I } \\
(n=55)\end{array}$ & $\begin{array}{l}\text { SEG II } \\
(n=123)\end{array}$ & $\begin{array}{l}\text { SEG III } \\
(n=32)\end{array}$ & $\begin{array}{l}\text { SEG IV } \\
(n=4)\end{array}$ & $\begin{array}{l}\text { SEG V } \\
(n=5)\end{array}$ \\
\hline Age, years & $54.4 \pm 12.4$ & $52.7 \pm 13.1$ & $55.4 \pm 12.2$ & $54.8 \pm 12.7$ & $50.3 \pm 11.8$ & $50.4 \pm 11.0$ \\
\hline Gender*, male (\%) & $156(71.2)$ & $46(83.6)$ & $85(69.1)$ & $20(62.5)$ & $3(75.0)$ & $2(40.0)$ \\
\hline BMI, kg/m² & $21.9 \pm 3.0$ & $22.2 \pm 2.9$ & $22.0 \pm 3.0$ & $22.1 \pm 2.9$ & $21.3 \pm 1.9$ & $18.5 \pm 2.8$ \\
\hline \multicolumn{7}{|l|}{ NAT, n (\%) } \\
\hline Chemoradiation & $176(80.4)$ & $42(76.4)$ & $102(82.9)$ & $32(100)$ & 0 & 0 \\
\hline Radiation alone & $29(13.2)$ & $11(20.0)$ & $18(14.6)$ & 0 & 0 & 0 \\
\hline Chemotherapy alone & $14(6.4)$ & $2(3.6)$ & $3(2.4)$ & 0 & $4(100)$ & $5(100)$ \\
\hline \multicolumn{7}{|l|}{ Histology, n (\%) } \\
\hline $\mathrm{AC}$ & $216(98.6)$ & $52(94.5)$ & $123(100)$ & $32(100)$ & $4(100)$ & $5(100)$ \\
\hline SCC & $3(1.4)$ & $3(5.5)$ & 0 & 0 & 0 & 0 \\
\hline Tumor location", cm & $5.1 \pm 2.4$ & $2.5 \pm 0.6$ & $5.1 \pm 0.8$ & $7.4 \pm 0.6$ & $10.5 \pm 1.0$ & $14.8 \pm 0.8$ \\
\hline Tumor thickness, mm & $11.3 \pm 7.3$ & $11.4 \pm 6.7$ & $11.4 \pm 7.8$ & $11.5 \pm 6.9$ & $11.3 \pm 3.2$ & $8.5 \pm 5.0$ \\
\hline $\mathrm{CEA}$ level ${ }^{*}, \mathrm{ng} / \mathrm{ml}$ & $14.5 \pm 34.0$ & $12.2 \pm 26.5$ & $15.1 \pm 37.7$ & $11.1 \pm 24.0$ & $24.9 \pm 34.0$ & $69.2 \pm 93.8$ \\
\hline \multicolumn{7}{|c|}{ Surgical procedures ${ }^{*}, \mathrm{n}(\%)$} \\
\hline Miles' & $102(46.6)$ & $47(85.4)$ & $48(39.0)$ & $5(15.6)$ & $2(50.0)$ & 0 \\
\hline Dixon's & $112(51.1)$ & $6(10.9)$ & $73(59.3)$ & $26(81.3)$ & $2(50.0)$ & $5(100)$ \\
\hline Hartmann's & $5(2.3)$ & $2(3.6)$ & $2(1.7)$ & $1(3.1)$ & 0 & 0 \\
\hline \multicolumn{7}{|l|}{ Pathological TNM, n (\%) } \\
\hline 0 & $53(24.2)$ & $12(21.8)$ & $31(25.2)$ & $9(28.1)$ & 0 & $1(20.0)$ \\
\hline I & $41(18.7)$ & $13(23.6)$ & $23(18.7)$ & $4(12.5)$ & $1(25.0)$ & 0 \\
\hline II & $72(32.9)$ & $16(29.1)$ & $41(33.3)$ & $10(31.3)$ & $3(75.0)$ & $2(40.0)$ \\
\hline III & $53(24.2)$ & $14(25.5)$ & $28(22.8)$ & $9(28.1)$ & 0 & $2(40.0)$ \\
\hline \multicolumn{7}{|l|}{ Adjuvant therapy, n (\%) } \\
\hline Chemoradiotherapy & $5(2.3)$ & $2(3.6)$ & $2(1.7)$ & $1(3.1)$ & 0 & 0 \\
\hline Chemotherapy & $214(97.7)$ & $53(96.4)$ & $121(98.3)$ & $31(96.9)$ & $4(100)$ & $5(100)$ \\
\hline
\end{tabular}




\section{The accuracy of transrectal ultrasound examination}

In the current study, the agreement of ultrasonographic staging and pathological staging was evaluated by $\mathrm{T}$ and $\mathrm{N}$ stages in each rectal segment, respectively. Meanwhile, the clinical staging via preoperative MSCT was utilized to verify the efficacy of TRUS in such cohorts. Generally, the overall accuracy of TRUS in staging of rectal cancer was remarkably superior to MSCT (64.8\% vs. $34.7 \%$, $P<0.001$ ).

As for the depth of tumor invasion (Table 3), the accuracy of T0 was 100\% in 20 cases, with T1 for seven $(43.8 \%)$ of 16 cases, $\mathrm{T} 2$ for $30(55.6 \%)$ of 54 cases, T3 for $78(78.0 \%)$ of 100 cases, T4 for $19(65.6 \%)$ of 29 cases, respectively. Downstaging was observed in 53 cases (24.2\%). The overall accuracy of $\mathrm{T}$ stage was $70.3 \%$ $(154 / 219)$. Specifically, in spite of nine cases from SEG $\mathrm{IV}$ and $\mathrm{V}$ groups, the most accurate $\mathrm{T}$ stage in each rectal segment was $\mathrm{T} 0$, and the most accurate location for $\mathrm{T}$ staging was SEG II $(78.0 \%)$. By using ROC analysis, the area under the curve (AUC) of T stage for TRUS was significantly increased compared with MSCT (0.524 vs. $0.358, P<0.001)$.

Table 3. Preoperative vs. pathological $T$ staging in five rectal segments

\begin{tabular}{|c|c|c|c|c|c|c|}
\hline & T stage & uT0 & uT1 & uT2 & uT3 & uT4 \\
\hline \multirow{5}{*}{$\begin{array}{l}\text { SEG I } \\
(1,3]^{*}, \mathrm{~cm}\end{array}$} & ypT0 & 2 & 3 & 4 & 4 & 0 \\
\hline & ypT1 & 0 & 3 & 2 & 1 & 0 \\
\hline & ypT2 & 0 & 0 & 6 & 3 & 2 \\
\hline & ypT3 & 0 & 0 & 3 & 17 & 1 \\
\hline & ypT4 & 0 & 0 & 0 & 1 & 3 \\
\hline \multirow{5}{*}{$\begin{array}{l}\text { SEG II } \\
(3,6], \mathrm{cm}\end{array}$} & урт0 & 16 & 5 & 6 & 5 & 0 \\
\hline & ypT1 & 0 & 4 & 0 & 0 & 1 \\
\hline & ypT2 & 0 & 0 & 19 & 1 & 3 \\
\hline & ypT3 & 0 & 0 & 1 & 46 & 2 \\
\hline & ypT4 & 0 & 0 & 0 & 1 & 13 \\
\hline \multirow{5}{*}{$\begin{array}{l}\text { SEG III } \\
(6,9], \mathrm{cm}\end{array}$} & урT0 & 2 & 1 & 6 & 2 & 0 \\
\hline & ypT1 & 0 & 0 & 0 & 0 & 0 \\
\hline & ypT2 & 0 & 0 & 4 & 1 & 0 \\
\hline & ypT3 & 0 & 0 & 0 & 13 & 0 \\
\hline & ypT4 & 0 & 0 & 0 & 1 & 2 \\
\hline \multirow{3}{*}{$\begin{array}{l}\text { SEG IV } \\
(9,12], \mathrm{cm}\end{array}$} & урТ2 & 0 & 0 & 0 & 0 & 1 \\
\hline & ypT3 & 0 & 0 & 1 & 1 & 0 \\
\hline & ypT4 & 0 & 0 & 0 & 1 & 0 \\
\hline \multirow{4}{*}{$\begin{array}{l}\text { SEG V } \\
(12,16], \mathrm{cm}\end{array}$} & урТ0 & 0 & 0 & 1 & 0 & 0 \\
\hline & урT2 & 0 & 0 & 1 & 0 & 0 \\
\hline & урТ3 & 0 & 0 & 0 & 1 & 0 \\
\hline & урT4 & 0 & 0 & 0 & 1 & 1 \\
\hline
\end{tabular}

* $(a, b]$ means a value larger than a, but no more than $b$. Abbreviations: uT,

ultrasonographic T stage; ypT, pathological T stage after neoadjuvant therapy; SEG, rectal segment.

As for the evaluation of LN metastasis (Table 4), the accuracy of N0 was $87.1 \%$ in 178 cases, with $56.8 \%$ for N1 in 37 cases and $100 \%$ for N2 in four cases, respectively. Downstaging was observed in only ten cases $(4.6 \%)$. The overall accuracy of $\mathrm{N}$ stage was
$82.2 \%(180 / 219)$, which was markedly better than clinical $\mathrm{N}$ stage $(82.2 \%$ vs. $60.7 \%, \mathrm{P}=0.006)$. In spite of nine cases from SEG IV and V groups, the most accurate $\mathrm{N}$ stage in each rectal segment was $\mathrm{N} 0$, and the most precise location for $\mathrm{N}$ staging was SEG II (88.6\%). Similarly, the AUC of N stage for TRUS was markedly increased compared with MSCT (0.369 vs. $0.123, P<0.001)$.

Table 4. Preoperative vs. pathological $N$ staging in five rectal segments

\begin{tabular}{lllll}
\hline & N stage & uN0 & uN1 & uN2 \\
\hline SEG I & ypN0 & 37 & 4 & 0 \\
$(1,3]^{*}, \mathrm{~cm}$ & ypN1 & 7 & 4 & 0 \\
& ypN2 & 1 & 1 & 1 \\
SEG II & ypN0 & 93 & 2 & 0 \\
$(3,6], \mathrm{cm}$ & ypN1 & 8 & 14 & 0 \\
& ypN2 & 1 & 3 & 2 \\
SEG III & ypN0 & 20 & 3 & 0 \\
$(6,9], \mathrm{cm}$ & ypN1 & 3 & 3 & 0 \\
& ypN2 & 1 & 1 & 1 \\
SEG IV & ypN0 & 3 & 1 & 0 \\
$(9,12], \mathrm{cm}$ & & & & \\
SEG V & ypN0 & 2 & 1 & 0 \\
$(12,16], \mathrm{cm}$ & ypN1 & 2 & 0 & 0 \\
\hline
\end{tabular}

* $(a, b]$ means a value larger than $a$, but no more than $b$. Abbreviations: $u N$, ultrasonographic $\mathrm{N}$ stage; $\mathrm{ypN}$, pathological $\mathrm{N}$ stage after neoadjuvant therapy; SEG, rectal segment.

The accuracy of TRUS in $\mathrm{T}$ staging, $\mathrm{N}$ staging and total staging had quite difference among various rectal segments (Table 5). The second segment, which was defined as the length distant from $3-6 \mathrm{~cm}$ to the anal verge, had the highest accuracy rates in all sorts of tumor staging than other rectal segments $(78.0 \%$ for $\mathrm{T}$ stage, $88.6 \%$ for $\mathrm{N}$ stage and $75.6 \%$ for total stage). The overall accuracy of ultrasonographic staging was $64.8 \%(142 / 219)$. The differences of total accuracy among the first three segments had statistical significance $\left(X^{2}=20.13, P<0.001\right)$. However, the overall accuracy of clinical staging was $34.7 \%$ (76/219), with not significant difference among each rectal segment $(\mathrm{P}=0.915)$.

Table 5. The accuracy of TRUS in each segment of rectum

\begin{tabular}{|c|c|c|c|c|c|}
\hline & \multicolumn{3}{|c|}{ Rectum Segment } & \multirow[b]{2}{*}{$\begin{array}{l}\text { IV }(9, \\
12] \mathrm{cm} \\
(\mathrm{n}=4)\end{array}$} & \multirow[b]{2}{*}{$\begin{array}{l}\mathrm{V}(12, \\
16) \mathrm{cm} \\
(\mathrm{n}=5)\end{array}$} \\
\hline & $\begin{array}{l}\text { I }(1,3] \mathrm{cm} \\
(\mathrm{n}=55)\end{array}$ & $\begin{array}{l}\text { II }(3,6] \mathrm{cm} \\
(\mathrm{n}=123)\end{array}$ & $\begin{array}{l}\text { III }(6,9] \mathrm{cm} \\
(\mathrm{n}=32)\end{array}$ & & \\
\hline $\begin{array}{l}\text { T stage* } \\
\text { Unequal, n (\%) }\end{array}$ & $24(43.6)$ & $27(22.0)$ & $11(34.4)$ & $3(75.0)$ & $2(40.0)$ \\
\hline Equal, n (\%) & $31(56.4)$ & $96(78.0)$ & $21(65.6)$ & $1(25.0)$ & $3(60.0)$ \\
\hline $\begin{array}{l}\text { N stage* } \\
\text { Unequal, n (\%) }\end{array}$ & $13(23.6)$ & $14(11.4)$ & $8(25.0)$ & $1(25.0)$ & $3(60.0)$ \\
\hline Equal, n (\%) & $42(76.4)$ & 109 (88.6) & $24(75.0)$ & $3(75.0)$ & $2(40.0)$ \\
\hline $\begin{array}{l}\text { TNM stage* } \\
\text { Unequal, n (\%) }\end{array}$ & $27(49.1)$ & $30(24.4)$ & $13(40.6)$ & $3(75.0)$ & $4(80.0)$ \\
\hline Equal, n (\%) & $28(50.9)$ & $93(75.6)$ & $19(59.4)$ & $1(25.0)$ & $1(20.0)$ \\
\hline
\end{tabular}




\section{Long-term outcomes and risk factors of inaccurate staging}

After radical surgery, 214 (97.7\%) of 219 patients had received adjuvant chemotherapy alone, with the rest of five patients receiving chemoradiotherapy. The median follow-up period was 52 (range, 14-98) months. The 5-year overall survival rate was $74.9 \%$ in this cohort population, and the average estimated overall survival time was 84.7 (95\% CI, 80.7-88.6) months. In details, the 5-year overall survival rate was $59.0 \%$ in SEG I, $79.0 \%$ in SEG II, $74.2 \%$ in SEG III, $100 \%$ in SEG IV and $100 \%$ in SEG V, respectively. A more
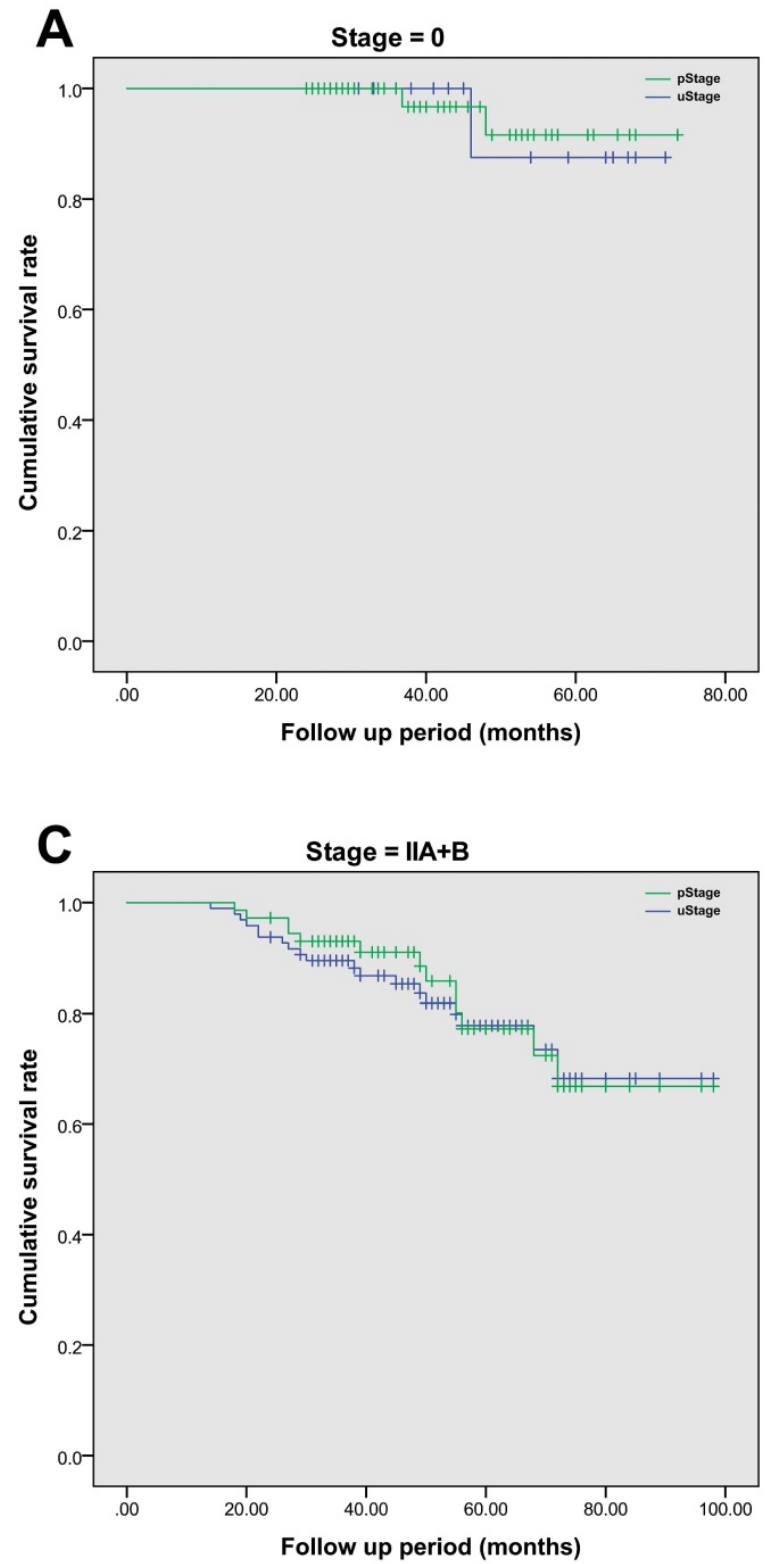

detailed survival analysis of patients with the same stage based on TRUS or pathology staging was performed by using Kaplan-Meier analysis (Figure 2). In each survival curve, the cumulative survival rate had no significant difference between two staging methods. By using Cox regression analysis, increased CEA level (over $5 \mu \mathrm{g} / \mathrm{L})$ prior to surgery $(P=0.004)$ and tumor involved segment (SEG IV and above, $P=0.011$ ) were correlated with inaccurate TRUS staging of rectal cancer. However, age, gender, body mass index, hemoglobin level and surgical procedures were not significant risk factors (Table 6).
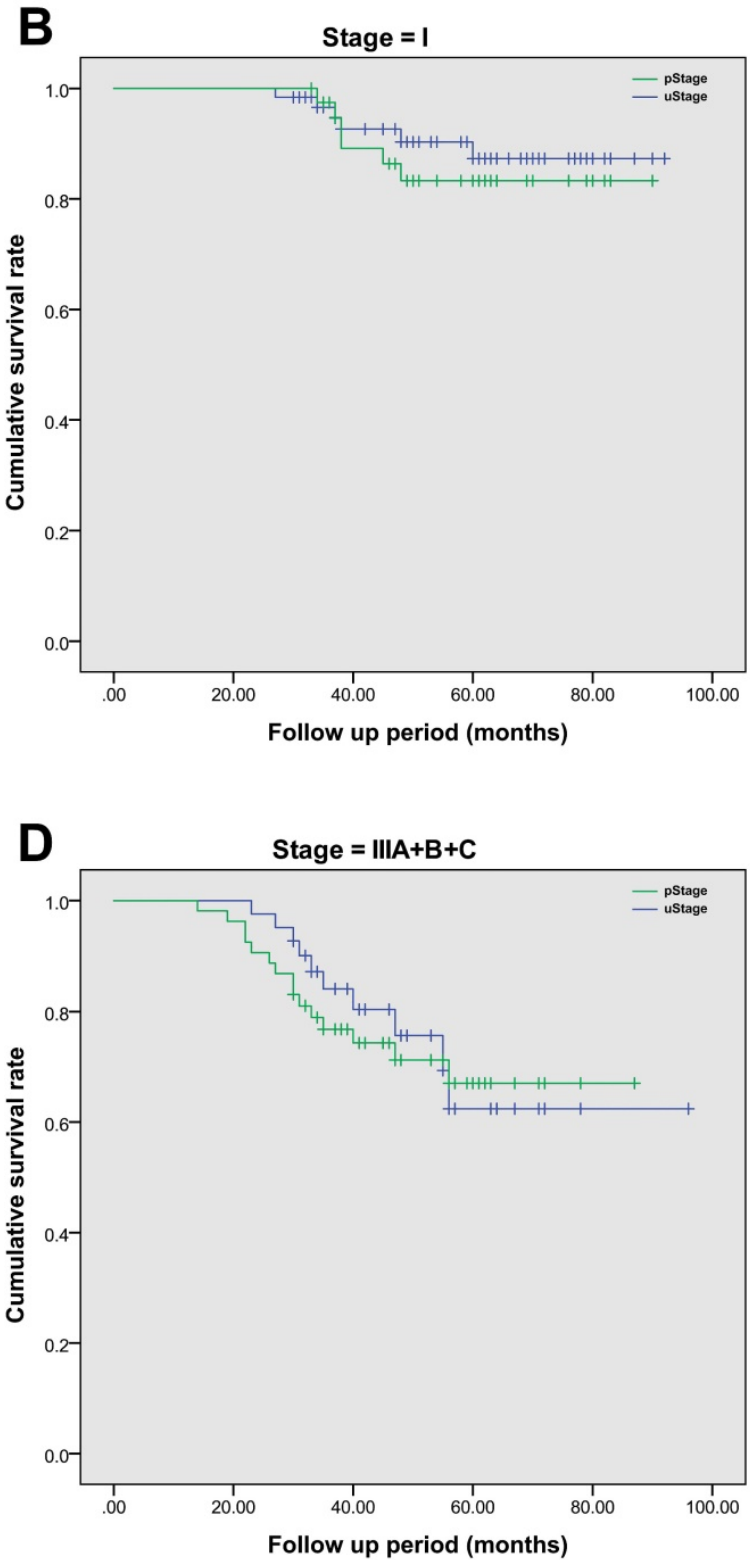

Figure 2. The comparison of cumulative overall survival between TRUS staging and pathological staging in patients with rectal cancer. Kaplan-Meier survival analysis was employed to compare difference between groups. Patients with the same tumor stage were grouped together. A. The comparison of overall survival in Stage 0 patients, $P=0.142$; B. The comparison of overall survival in Stage I patients, $P=0.467 ; C$. The comparison of overall survival in Stage II patients, with both stage IIA and IIB included cumulatively, $\mathrm{P}=0.579$; D. The comparison of overall survival in Stage III patients, with all sub-stages included together, $\mathrm{P}=0.278$. 
Table 6. Risk factors of inaccurate diagnosis of TRUS for rectal cancer staging

\begin{tabular}{|c|c|c|c|c|}
\hline \multirow[t]{2}{*}{ Factor } & \multirow[t]{2}{*}{ B value } & \multirow[t]{2}{*}{$P$ value } & \multicolumn{2}{|l|}{$95 \% \mathrm{CI}$} \\
\hline & & & lower bound & Upper bound \\
\hline Age & 0.528 & 0.174 & 0.848 & 3.389 \\
\hline Gender & -0.340 & 0.355 & 0.347 & 1.459 \\
\hline BMI & -0.402 & 0.521 & 0.245 & 1.865 \\
\hline $\mathrm{Hb}$ level & -0.104 & 0.799 & 0.405 & 2.004 \\
\hline CEA level & 0.945 & 0.004 & 1.324 & 5.002 \\
\hline Surgical Procedures & -0.048 & 0.132 & 0.279 & 1.381 \\
\hline Tumor location & 1.533 & 0.011 & 0.090 & 0.847 \\
\hline \multicolumn{5}{|c|}{$\begin{array}{l}\text { Cox regression analysis of inaccurate evaluation of TRUS compared with } \\
\text { pathological tumor staging, with Enter method utilized for covariate inclusion. } \\
\text { Abbreviations: BMI, body mass index; } \mathrm{Hb} \text {, hemoglobin; CEA, carcinoembryonic } \\
\text { antigen; B, slope of the regression; } \mathrm{CI} \text {, confidential interval. Cutoff values for each } \\
\text { factor: age, } 60 \mathrm{yrs} \text {; gender, male; } \mathrm{BMI}, 18.5-25.0 \mathrm{~kg} / \mathrm{m}^{2} ; \mathrm{Hb}, 110 \mathrm{~g} / \mathrm{ml} \text { for the female } \\
\text { and } 120 \mathrm{~g} / \mathrm{ml} \text { for the male; CEA, } 5 \mu \mathrm{g} / \mathrm{L} \text {; Surgical procedures, sphincter conserving } \\
\text { or not; tumor location, segment } \mathrm{IV} \text { and above. } P<0.05 \text { indicates statistical } \\
\text { significance. }\end{array}$} \\
\hline
\end{tabular}

\section{Discussion}

In the current study, the overall accuracy of TRUS for staging rectal cancer after NAT was $64.8 \%$, as compared to $34.7 \%$ for conventional clinical stage via MSCT. Importantly, analysis of different locations of rectal cancer by TRUS revealed a huge diversity of diagnostic accuracy compared to histological results. Our findings indicated that an optimal accuracy could be obtained when the tumor location was 3-6 cm above the anal verge. Moreover, our long-term data suggested that TRUS staging had a comparable predictive value to histopathology staging for overall survival.

In the view of anatomy, the rectum is typically structured. It could be simply divided into two parts based on peritoneal reflection: above and below the reflection, respectively. Besides, it can be naturally separated by muscle spaces into three segments: internal and external sphincters, internal sphincter and levator ani, and internal sphincter only. However, in clinical practice, the anatomic boundaries may be hardly determined due to tumor infiltration; as a result, a digital blocking separation based on distance from the anal verge is proposed due to easier manipulation and data collection. In our study, the rectum is divided into five consecutive segments, rather than the conventional lower, middle and upper third. This separation method is modified from reported four segments theory [16]. It actually excludes the anal canal and significantly reduces the segment span in low-mid thirds of the rectum. To our knowledge, this modified method is first applied to locate rectal cancers, which would adequately enhance the power of ultrasonographic staging. In addition, this method theoretically makes rectal segments get close to anatomic structures. Our findings first detect a fixed region of the lower third rectum where the accuracy of ultrasonographic restaging would be most comparable to pathological staging.

It is generally recognized that TRUS is simple and inexpensive to perform as compared to MSCT or MRI. By using TRUS, the intrinsic layers of rectum and adjacent muscles can be easily discerned in view of alternating hyper- and hypo-echoic qualities [17]. Its value in the evaluation of invasive depth has been confirmed, especially for initial assessment. However, its role in secondary $\mathrm{T}$ staging after NAT remains controversial. The accuracy of $\mathrm{T}$ restaging was quite variable across previous studies, ranging from $38.3-75 \%$ [18-25]. Our study indicated that the accuracy of $\mathrm{T}$ restaging was $70.3 \%$, which was in accordance with similar earlier investigations. Besides, malignant LNs with peritumoral location have a hypoechoic aspect, rounded shape, $5-7 \mathrm{~mm}$ in size $[26,27]$, which could share common features with reactive-inflammatory LNs or adjacent tumor. Hence, the diagnostic value of TRUS is reported to be inferior to that of transrectal MRI when assessing metastatic LNs (overall accuracy, $74 \%$ vs. $82 \%$ ) [28]. According to available data, TRUS is superior to MRI in staging early cancers and defining the infiltration of the anal sphincter, but relatively inferior in restaging after NAT and screening for recurrent cancer [12, 29].

The limitations of this study stem from its retrospective design and should be addressed. All included patients have received neoadjuvant treatment, especially regional radiotherapy, to achieve downstaging for a subsequent radical resection and improved overall survival. This induction treatment would unavoidably interfere with ultrasonographic $\mathrm{T}$ and $\mathrm{N}$ staging. Previous studies have reported that the accuracy without NAT is $38.3 \%$ to $92.8 \%$ for predication of $\mathrm{T}$ stage and $72.6 \%$ for $\mathrm{N}$ stage, respectively $[23,30]$. Besides, MRI staging has not been a routine practice in our center within the study period, hence, it is impossible to evaluate its value in preoperative evaluation of rectal cancer among various rectal segments. A prospective study with similar design including MRI staging is still under the way in our center. At last, the sample size in SEG IV and V is quite small, perhaps restricting the validity of accuracy comparison among rectal segments. We believe that a well-designed large-scale study including various imaging methods in rectal cancer staging is essential to better define their roles in cancer assessment and guide the subsequent treatment.

\section{Conclusion}

In summary, transrectal ultrasound is still a valuable method for assessing and staging of rectal 
cancer, especially for lower third rectal cancer following neoadjuvant therapy. The application of transrectal ultrasound for precisely evaluation of tumor stage would be most accurate when tumors located 3-6 $\mathrm{cm}$ above the anal verge.

\section{Compliance with ethical standards}

\section{Ethical approval}

All procedures performed in studies involving human participants were in accordance with the ethical standards of the institutional and/or national research committee and with the 1964 Helsinki declaration and its later amendments or comparable ethical standards.

\section{Informed consent}

Written informed consent was obtained from all individuals included in the study.

\section{Acknowledgement}

This work was supported by grants from National Natural Science Foundation of China (No. 81401307) and Medical Science and Technology Research Fund Project in GuangDong province (A2015112).

\section{Author Contributions}

Conceived and designed the study: YY, YH. Performed the clinical review and data retrieval: $Y R$, JY, YW, WX. Analyzed the data: YY, YR, JY. Contributed reagents/materials/analysis tools: JX, MT, SC. Wrote the paper: YR, JY, YY. Designed the methodology in analysis: YY, MT, SC.

\section{Conflicts of interest}

The authors declare no conflicts of interest.

\section{References}

1. Siegel RL, Miller KD, Jemal A. Cancer statistics, 2016. CA Cancer J Clin. 2016; 66: 7-30

2. Bozzetti F. Prognostic significance of radial margins of clearance in rectal cancer. Br J Surg. 1996; 83: 1798

3. Gimbel MI, Paty PB. A current perspective on local excision of rectal cancer. Clin Colorectal Cancer. 2004; 4: 26-35; discussion 36-27.

4. Gerard JP, Chapet O, Nemoz C, Hartweig J, Romestaing P, Coquard R, et al. Improved sphincter preservation in low rectal cancer with high-dose preoperative radiotherapy: the lyon R96-02 randomized trial. J Clin Oncol. 2004; 22: 2404-2409.

5. Beynon J. An evaluation of the role of rectal endosonography in rectal cancer. Ann R Coll Surg Engl. 1989; 71: 131-139.

6. Tapan U, Ozbayrak M, Tatli S. MRI in local staging of rectal cancer: an update. Diagn Interv Radiol. 2014; 20: 390-398.

7. Granero-Castro P, Munoz E, Frasson M, Garcia-Granero A, Esclapez P, Campos S, et al. Evaluation of mesorectal fascia in mid and low anterior rectal cancer using endorectal ultrasound is feasible and reliable: a comparison with MRI findings. Dis Colon Rectum. 2014; 57: 709-714.

8. Marone P, de Bellis M, D'Angelo V, Delrio P, Passananti V, Di Girolamo E, et al. Role of endoscopic ultrasonography in the loco-regional staging of patients with rectal cancer. World J Gastrointest Endosc. 2015; 7: 688-701.

9. Kav T, Bayraktar Y. How useful is rectal endosonography in the staging of rectal cancer? World J Gastroenterol. 2010; 16: 691-697.

10. Truong S, Hartung R, Rohrmann D. [Preoperative staging and follow-up in rectal cancer using endorectal sonography]. Zentralbl Chir. 1986; 111: 333-338.
11. Rifkin MD, Wechsler RJ. A comparison of computed tomography and endorectal ultrasound in staging rectal cancer. Int J Colorectal Dis. 1986; 1: 219-223.

12. Xu D, Ju HX, Qian CW, Jiang F. The value of TRUS in the staging of rectal carcinoma before and after radiotherapy and comparison with the staging postoperative pathology. Clin Radiol. 2014; 69: 481-484.

13. Compton CC, Greene FL. The staging of colorectal cancer: 2004 and beyond. CA Cancer J Clin. 2004; 54: 295-308

14. Song W, Yuan Y, Peng J, Chen J, Han F, Cai S, et al. The delayed massive hemorrhage after gastrectomy in patients with gastric cancer: characteristics, management opinions and risk factors. Eur J Surg Oncol. 2014; 40: 1299-1306.

15. Wachter S, Gerstner N, Goldner G, Potzi R, Wambersie A, Potter R. Endoscopic scoring of late rectal mucosal damage after conformal radiotherapy for prostatic carcinoma. Radiother Oncol. 2000; 54: 11-19.

16. Cao F, Ma TH, Liu GJ, Wen YL, Wang HM, Kuang YY, et al. Correlation between Disease Activity and Endorectal Ultrasound Findings of Chronic Radiation Proctitis. Ultrasound Med Biol. 2017; 43: 2182-2191.

17. Kumar A, Scholefield JH. Endosonography of the anal canal and rectum. World J Surg. 2000; 24: 208-215.

18. Liersch T, Langer C, Jakob C, Müller D, Ghadimi B, Siemer A, et al. Preoperative diagnostic procedures in locally advanced rectal carcinoma (> or $=\mathrm{T} 3$ or $\mathrm{N}+$ ). What does endoluminal ultrasound achieve at staging and restaging (after neoadjuvant radiochemotherapy) in contrast to computed tomography? Der Chirurg; Zeitschrift fur alle Gebiete der operativen Medizen. 2003; 74: 224-234.

19. Vanagunas A, Lin DE, Stryker SJ. Accuracy of endoscopic ultrasound for restaging rectal cancer following neoadjuvant chemoradiation therapy. Am J Gastroenterol. 2004; 99: 109-112.

20. Maor Y, Nadler M, Barshack I, Zmora O, Koller M, Kundel Y, et al. Endoscopic ultrasound staging of rectal cancer: diagnostic value before and following chemoradiation. J Gastroenterol Hepatol. 2006; 21: 454-458.

21. Maretto I, Pomerri F, Pucciarelli S, Mescoli C, Belluco E, Burzi S, et al. The potential of restaging in the prediction of pathologic response after preoperative chemoradiotherapy for rectal cancer. Ann Surg Oncol. 2007; 14: 455-461.

22. Radovanovic Z, Breberina M, Petrovic T, Golubovic A, Radovanovic D. Accuracy of endorectal ultrasonography in staging locally advanced rectal cancer after preoperative chemoradiation. Surg Endosc. 2008; 22: 2412-2415.

23. Huh JW, Park YA, Jung EJ, Lee KY, Sohn SK. Accuracy of endorectal ultrasonography and computed tomography for restaging rectal cancer after preoperative chemoradiation. J Am Coll Surg. 2008; 207: 7-12.

24. Mezzi G, Arcidiacono PG, Carrara S, Perri F, Petrone MC, De Cobelli F, et al. Endoscopic ultrasound and magnetic resonance imaging for re-staging rectal cancer after radiotherapy. World J Gastroenterol. 2009; 15: 5563-5567.

25. Martellucci J, Scheiterle M, Lorenzi B, Roviello F, Cetta F, Pinto E, et al. Accuracy of transrectal ultrasound after preoperative radiochemotherapy compared to computed tomography and magnetic resonance in locally advanced rectal cancer. Int J Colorectal Dis. 2012; 27: 967-973.

26. Bianchi P, Ceriani C, Palmisano A, Pompili G, Passoni GR, Rottoli M, et al. A prospective comparison of endorectal ultrasound and pelvic magnetic resonance in the preoperative staging of rectal cancer. Ann Ital Chir. 2006; 77: $41-46$.

27. Akbari RP, Wong WD. Endorectal ultrasound and the preoperative staging of rectal cancer. Scand J Surg. 2003; 92: 25-33.

28. Kwok H, Bissett IP, Hill GL. Preoperative staging of rectal cancer. Int J Colorectal Dis. 2000; 15: 9-20.

29. Marone P, de Bellis M, D'Angelo V, Delrio P, Passananti V, Di Girolamo E, et al. Role of endoscopic ultrasonography in the loco-regional staging of patients with rectal cancer. World Journal of Gastrointestinal Endoscopy. 2015; 7: 688-701.

30. Barbaro B, Schulsinger A, Valentini V, Marano P, Rotman M. The accuracy of transrectal ultrasound in predicting the pathological stage of low-lying rectal cancer after preoperative chemoradiation therapy. Int J Radiat Oncol Biol Phys. 1999; 43: 1043-1047. 